\title{
O avanço do COVID-19 na Amazônia legal: Uma análise do crescimento de casos na cidade de Gurupi, Tocantins.
}

The advance of COVID-19 in the legal amazon: an analysis of case growth in the city of Gurupi, Tocantins.

Jéssyka Viana Valadares Franco ${ }^{1}$, Thiago Franco Oliveira².

\section{RESUMO}

A doença causada pelo novo coronavírus (SARS-CoV-2) surgiu em dezembro de 2019 na cidade de Wuhan, província de Hubei, China, e apresentou um crescimento exponencial naquele país, alastrando-se posteriormente para todos os continentes, sendo classificada como uma pandemia. Por esta razão, este trabalho objetiva através do estudo epidemiológico da doença, analisar motivos do avanço de casos na cidade de Gurupi, To. Foi realizado um estudo quantitativo, descritivo, transversal no período dos meses de fevereiro à maio do ano 2020, através de consulta aos boletins oficiais emitidos pela Secretaria Estadual de Saúde do Estado do Tocantins e Secretaria Municipal de Saúde de Gurupi. Foram registrados 32 casos de pessoas infectadas no período analisado, apontando um aumento de mais de $550 \%$ em relação ao primeiro dia. Observou-se que caminhoneiros são pessoas altamente expostas ao vírus e com elevada capacidade de transmissão. Apresentou-se diversas hipóteses motivadoras do avanço substancial de casos de pessoas contaminadas na cidade, dentre as quais a mais relevante foi sua localização

Palavras-chave: COVID-19. Coronavírus. Pandemia. Caminhoneiros. Hábitos.

\section{ABSTRACT}

The disease caused by the new coronavirus (SARS-CoV-2) emerged in December 2019 in the city of Wuhan, Hubei province, China, and showed exponential growth in that country, spreading to all continents, being classified as a pandemic. For this reason, this study aims, through the epidemiological study of the disease, to analyze reasons for the advance of cases in the city of Gurupi, To. A quantitative, descriptive, cross-sectional study was carried out from February to May of the year 2020, by consulting the official bulletins issued by the State Health Department of the State of Tocantins and the Municipal Health Department of Gurupi. There were 32 cases of infected people in the analyzed period, indicating an increase of more than $550 \%$ in relation to the first day. It was observed that truck drivers are people highly exposed to the virus and with high transmission capacity. Several hypotheses were presented motivating the substantial advance of cases of infected people in the city, among which the most relevant was its location

Keywords: COVID-19. Coronavirus. Pandemic. Truckers. Habits.
1 Bacharel em Farmácia Generalista pelo Centro Universitário Tocantinense Presidente Antonio Carlos UNITPAC - Araguaína. Graduanda em Medicina pela Universidade de Gurupi - UNIRG. Pós Graduanda em Farmácia Clinica e Hospitalar; Citologia Oncótica; e Atenção primária à saúde com ênfase em saúde da família.

E-mail: jessykavviana@gmail.com

${ }^{2}$ Bacharel em Direito pela Faculdade Católica Dom Orione - FACDO. Especialista em Direito Eleitoral e Administrativo pela Universidade Federal do Tocantins (UFT) e em Direito Público pela Faculdade ITOP. Mestrando em Desenvolvimento Regional pela Universidade Federal do Tocantins (UFT). Docente no Curso de Direito da Universidade de Gurupi - UNIRG 


\section{INTRODUCAO}

O coronavírus é um vírus zoonótico (transmissível de um animal ao homem), pertence a uma grande família de RNA da ordem Nidovirales, da família Coronaviridae. ${ }^{8}$ Segundo Claudio Márcio Amaral de Oliveira Lima ${ }^{8}$ no ano de 1937 o vírus foi isolado pela primeira vez, e descrito no ano de 1965. Morfologicamente são denominados dessa maneira por apresentar a forma de coroa (em latim: corona $=$ coroa) ${ }^{8}$

Estruturalmente o vírus contém receptores em sua superfície (proteína S), e quando vistos ao microscópio eletrônico o vírus mede aproximadamente 50-200 nm de diâmetro, possuindo proteínas estruturais, dentre elas destaca a: proteína $\mathrm{E}$ (envelope), proteína M (membrana) e proteína $\mathrm{N}$ (nucleocapsídeo) e proteína S (espiga). ${ }^{7}$

Na cama mais externa apresenta o envelope viral, formada pela união da proteína $\mathrm{N}$ que contém o genoma do RNA mais as proteínas $S$, E e M. Visto que a proteína $S$ é a proteína que permite que o vírus se ligue à membrana celular de uma célula hospedeira. As características patológicas são amplas, provocando a partir de um resfriado comum a síndromes respiratórias graves. ${ }^{7}$

Existem diversos tipos de corona vírus, que atualmente são conhecidos como: alfa coronavírus HCoV-229E e alfa coronavírus HCoV-NL63, beta coronavírus HCoV-OC43 e beta coronavírus HCoV-HKU1, SARS-CoV, MERS-CoV e SARSCoV-2, um novo coronavírus descrito no final de 2019 após casos registrados na China, este último provoca a doença chamada de COVID-19. ${ }^{8}$

Foram destacadas grandes epidemias relacionadas ao coronavírus, sendo que a primeira ocorreu no ano de 2002 na China caracterizada por infecções respiratórias graves causadas pela Síndrome Respiratória Aguda Grave - Coronavírus, denominada SARS-CoV. ${ }^{11}$

A segunda epidemia ocorreu em 2012 no Oriente Médio, onde foi relatado a Síndrome Respiratória Aguda e Grave e o vírus foi chamado de Síndrome Respiratória no Oriente Médio - Coronavírus (MERS-CoV). ${ }^{7,8}$

Em dezembro do ano de 2019 um novo coronavírus chamado de COVID -19, que é objeto desse estudo, foi descrito após casos registrados na China com um surto de pneumonia na cidade de Wuhan, sendo que observou-se que as pessoas admitidas haviam trabalhado no Mercado Atacadista de Frutos do Mar de Huanan, que por sua vez comercializa aves vivas, produtos aquáticos e vários tipos de animais selvagens. $\mathrm{Na}$ 
China o agente causador do COVID-19 foi o severe acute respiratory syndrome coronavírus 2 ou SARS-CoV-2. ${ }^{2}$

A disseminação da doença anteriormente mencionada se propagou rapidamente resultando em uma pandemia, que tem afetado diversos, países, dentre os quais o Brasil. ${ }^{2}$ No dia 30 de janeiro de 2020, a Organização Mundial de Saúde (OMS) declarou que o surto do novo coronavírus constitui uma Emergência de Saúde Pública de Importância Internacional (ESPII) o mais alto nível de alerta da Organização, conforme previsto no Regulamento Sanitário Internacional. ${ }^{4}$

A decisão da OMS buscou aprimorar a coordenação, a cooperação e a solidariedade global para interromper a propagação do vírus. Essa decisão aprimora a coordenação, a cooperação e a solidariedade global para interromper a propagação do vírus. ${ }^{4}$

Diante da situação calamidade pública o Brasil no dia 22 de janeiro de 2020 criou o Centro de Operações de Emergências (COE) do Ministério da Saúde para o planejamento, organização e o monitoramento da situação epidemiológica. ${ }^{10}$

No dia 20 de março de 2020, foi reconhecido em todo território nacional, o estado de transmissão comunitária do coronavírus (COVID-19), tal mudança na classificação não se deve à gravidade da doença e sim à mudança na forma de transmissão que a doença tem apresentado. ${ }^{10}$

A Organização Pan- Americana de Saúde (OPAS/OMS), afirma que é a sexta vez na história da humanidade que uma Emergência de Saúde Pública de Importância Internacional é declarada. As demais foram: 25 de abril de 2009 - pandemia de H1N1, 05 de maio de 2014 - disseminação internacional de poliovírus, 08 agosto de 2014 - surto de Ebola na África Ocidental, de fevereiro de 2016 - vírus zika e aumento de casos de microcefalia e outras malformações congênitas, 18 maio de 2018 - surto de ebola na República Democrática do Congo. ${ }^{11}$

Baseados em estudos de outros tipos de coronavírus e no pouco conhecimento que se tem a transmissão do COVID-19 se dá por contato com gotículas (tosse, espirro) contaminadas pelo vírus ou com mucosas da pessoa exposta provenientes do sistema respiratório, através do contato direto ou indireto, bem como após tocar em superfícies contaminadas e, em seguida, na boca, olhos ou nariz. ${ }^{2}$

Também são consideradas possíveis contaminantes: sangue, secreções respiratórias, ambiente de serviço de saúde podendo ser um potencial disseminador/área 
de transmissão da doença. ${ }^{2}$ Mesmo com pouco conhecimento cientifico sobre o vírus, estudos evidenciam a alta velocidade de disseminação e capacidade de provocar mortes. ${ }^{1}$

A sintomatologia clínica da infecção causada pelo vírus apresenta uma grande amplitude, podendo variar de resfriado até uma pneumonia grave. Inicialmente o quadro clínico é caracterizado como uma síndrome gripal. ${ }^{5,7,8}$

Pessoas com COVID-19 geralmente desenvolvem sinais e sintomas, incluindo problemas respiratórios leves e febre persistente, em média de 5 a 6 dias após a infecção (período médio de incubação de 5 a 6 dias, com intervalo de 1 a 14 dias), tosse, cansaço, falta de ar no início dos sintomas. Outros sintomas menos comuns incluem: garganta seca/dor de garganta, cefaleia, tosse com expectoração e ou hemoptise, podendo apresentar também sintomas gastrointestinais como diarreia e náuseas precedendo febre e sintomas respiratórios. ${ }^{1,8,9}$

O diagnóstico para confirmar o novo coronavírus é realizado através de exames de biologia molecular que detecta o RNA (Ácido Ribonucleico) viral, por meio do reversetranscriptase polymerase chain reaction (RT-PCR, reação em cadeia da polimerase com transcrição reversa). ${ }^{2,4,7}$

A coleta é através de materiais respiratórios, ou seja, aspirado da nasofaringe ou swabscombinado (nasal/oral) ou também amostra de secreção respiratória inferior (escarro, lavado traqueal ou lavado broncoalveolar). ${ }^{2,5,8}$

De acordo com as orientações do Ministério da Saúde são de tamanha relevância as medidas de prevenção da disseminação do coronavírus, que incluem: a lavagem das mãos com água e sabão ou sua higienização com álcool em gel; a "etiqueta respiratória", que consiste em cobrir o nariz e a boca ao espirrar ou tossir; o distanciamento social; o não compartilhamento de objetos de uso pessoal, como copos e talheres; e o hábito de se manter a ventilação nos ambientes. ${ }^{8,9,4}$

Estudos ainda não são esclarecedores, mas com bases nos registros epidemiológicos dos infectados, evidencia-se que pacientes idosos e com comorbidades crônicas possuem risco maior de desenvolver a doença com maior gravidade, dentre eles estão pessoas acima de 60 anos, doença cardiovascular, diabetes, doença pulmonar crônica, imunossupressão, doença cerebrovascular, insuficiência renal, gestantes. ${ }^{8}$

Desse modo, o objetivo principal desta pesquisa é fazer um estudo epidemiológico e analisar o avanço de casos do COVID-19 na cidade de Gurupi, Tocantins, através de uma análise dos boletins informativos e comunicados oficiais emitidos pela Secretaria Estadual 
de Saúde do Estado do Tocantins e da Secretaria Municipal de Saúde da Cidade Gurupi, além de apontar hipóteses que levaram ao aumento do vírus em tal localidade.

A cidade de Gurupi fica no limite divisório de águas entre o Rio Araguaia e o Rio Tocantins, ás margens da BR 153 (rodovia Belém- Brasília), e é a terceira maior cidade do Estado, sendo o polo regional de toda a região sul do Tocantins, sua população estimada é de 86.647 pessoas com densidade demográfica de 41,80 habitantes por quilômetro quadrado, ficando ao sul do Estado do Tocantins a $214 \mathrm{~km}$ de Palmas, capital do Estado a 612 km de Goiânia e a 596 km de Brasília. ${ }^{17}$

Localizada no centro geodésico do país, sendo este o principal corredor de interligação entre o sul e o norte do mesmo, contando com um intenso trafego de veículos de cargas, e por ser uma cidade regional, com infraestrutura considerável, atraí além de caminhoneiros, diversas pessoas que utilizam-se da rodovia diariamente, alterando consideravelmente a população da cidade, porém não são contabilizados no censo demográfico. ${ }^{17}$

\section{MATERIAIS E METODOS}

Trata-se de uma pesquisa bibliográfica com estudo quantitativo, descritivo, transversal realizado no período dos meses de abril e maio do ano 2020, por meio de artigos científicos, análise de boletins oficiais emitidos pela Secretaria Estadual de Saúde do Estado do Tocantins e Secretaria Municipal de Saúde de Gurupi, além de outros comunicados oficiais.

Assim, o que se buscou foi um levantamento do avanço de casos do novo coronavírus na Amazônia Legal, mais especificamente na cidade de Gurupi, Estado do Tocantins. Neste sentido vale explicar que no Brasil as divisões regionais foram produzidas, em geral, para servir à implantação de políticas estatais, neste a Amazônia Legal, que corresponde a $60 \%$ do território brasileiro, recebeu essa denominação em 1966, para a realização de políticas específicas, para fins deste artigo a unidade de análise está baseada em um do nos nove estados (Acre - AC, Amapá - AP, Amazonas AM, Pará - PA, Rondônia - RO, Roraima - RR, Mato Grosso - MT, Tocantins - TO e o estado do Maranhão - MA), que compõem a Amazônia Legal (IBGE, 2016), ou seja, os estados da Região Norte.

Assim buscou-se realizar a pesquisa em duas etapas, sendo a primeira, a identificação da questão norteadora do estudo, a busca ou amostragem da literatura, 
coleta de dados, análise crítica dos dados encontrados, discussão dos resultados e a apresentação da revisão. A segunda se deu através da leitura de artigos científicos selecionados junto aos seguintes bancos de dados: Literatura Latino-American e do Caribe em Ciências da Saúde (LILACs), google acadêmico, revistaScielo e biblioteca Virtual em Saúde (BVS), os quais foram organizados e selecionados por meio de um gerenciador de referência - sistema on-line Paperpile, bem como de dados oficiais publicados pelo governo local, estadual e federal.

A coleta de informações se deu através de consulta aos bancos de dados científicos, bem como nos comunicados através de boletins diários de informações sobre o COVID19, publicados no site da prefeitura de Gurupi e do Governo do Estado do Tocantins, entre os meses de fevereiro e maio de 2020.

Foram selecionados artigos científicos recentes relacionados ao estudo do COVID19, bem como informações oficiais publicadas pelo poder público, sendo excluídas as informações irrelevantes para o estudo do avanço de casos na cidade de Gurupi.

Para análise dos dados foi utilizada a estatística descritiva simples, através de ferramentas do Microsoft Office 2015, especificamente do Excel, para estabelecer a evolução dos casos confirmados do novo coronavírus em Gurupi.

\section{RESULTADOS}

Segundo consta nos boletins oficiais do Ministério da Saúde, disponíveis no portal https://www.saude.gov.br/boletins-epidemiologicos, o Brasil no dia 08 de maio de 2020, contava com 135.106 pessoas que testaram positivo, incluídos nesses números pessoas em tratamento, em isolamento e recuperados, ao passo que o Estado do Tocantins, segue no mesmo ritmo contando em tal data com 494 (quatrocentos e noventa e quatro) pessoas testadas positivas. A cidade de Gurupi, no dia 08 de maio de 2020 contava com 22 pessoas testadas positivas para o novo vírus.

Em que pese o gráfico 1 mostrar uma rápida evolução, do primeiro caso confirmando no Brasil, ao primeiro caso confirmado no Tocantins se passaram 22 dias, o que comparado a cidade Gurupi, foram 42 dias, ou seja um prazo razoável para a elaboração de um plano de contingenciamento da propagação do vírus, porém isso não foi o suficiente conforme pode ser visto no gráfico, o que pode ser justificado pela fácil propagação do COVID-19. 


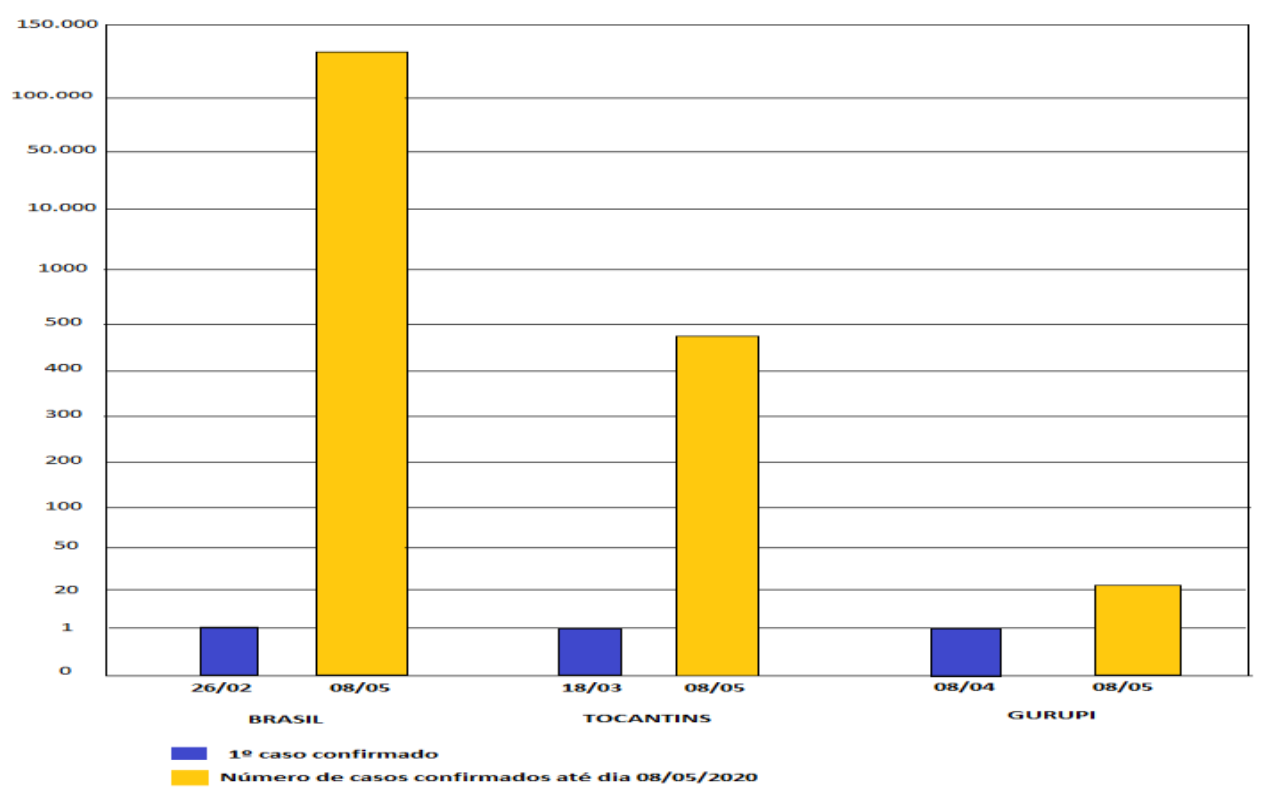

Gráfico 1. Comparativo dos casos confirmados entre o Brasil, Tocantins e Gurupi.

O número de pessoas confirmadas em Gurupi representa menos de 0,03\% da população da cidade, que é de 86.647 mil habitantes, porém os boletins revelam um crescimento exponencial nos últimos 10 dias, evoluindo de 04 casos no dia $1^{\underline{a}}$ de maio de 2020 para 22 no dia 08 de maio de 2020 , ou seja, um crescimento de $550 \%$, conforme pode ser visto no gráfico 2 abaixo.

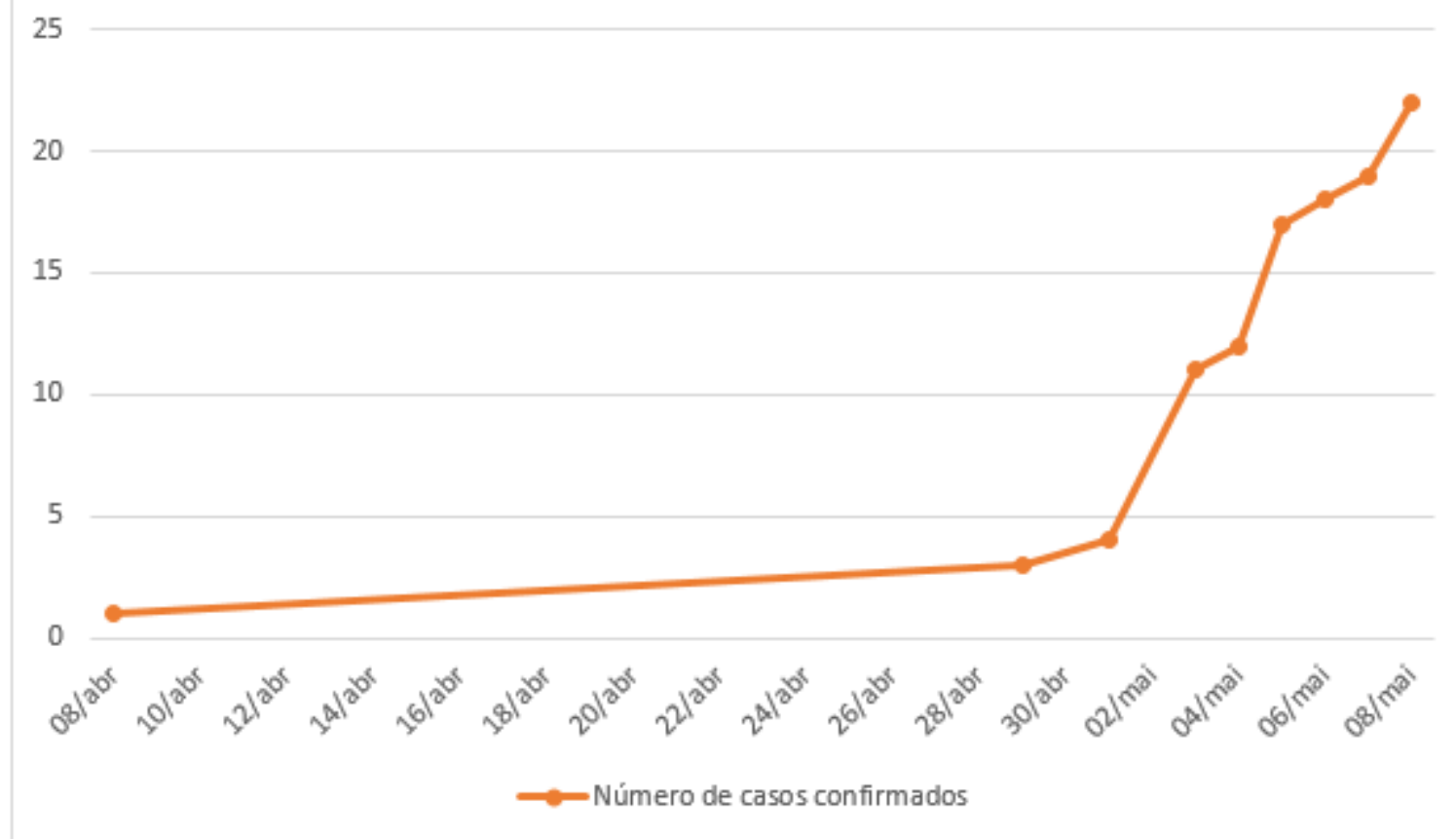

Gráfico 2: Evolução de casos confirmados na cidade Gurupi, TO. 
O gráfico a seguir (3) apresenta variáveis quantitativas de novos casos de COVID19 mais especificamente entre os dias 8 e 10 de maio de 2020, representando um aumento significativo de $68,75 \%$ em dois dias, uma vez que passou de 22 casos confirmados no dia 08 para 32 no dia 10.

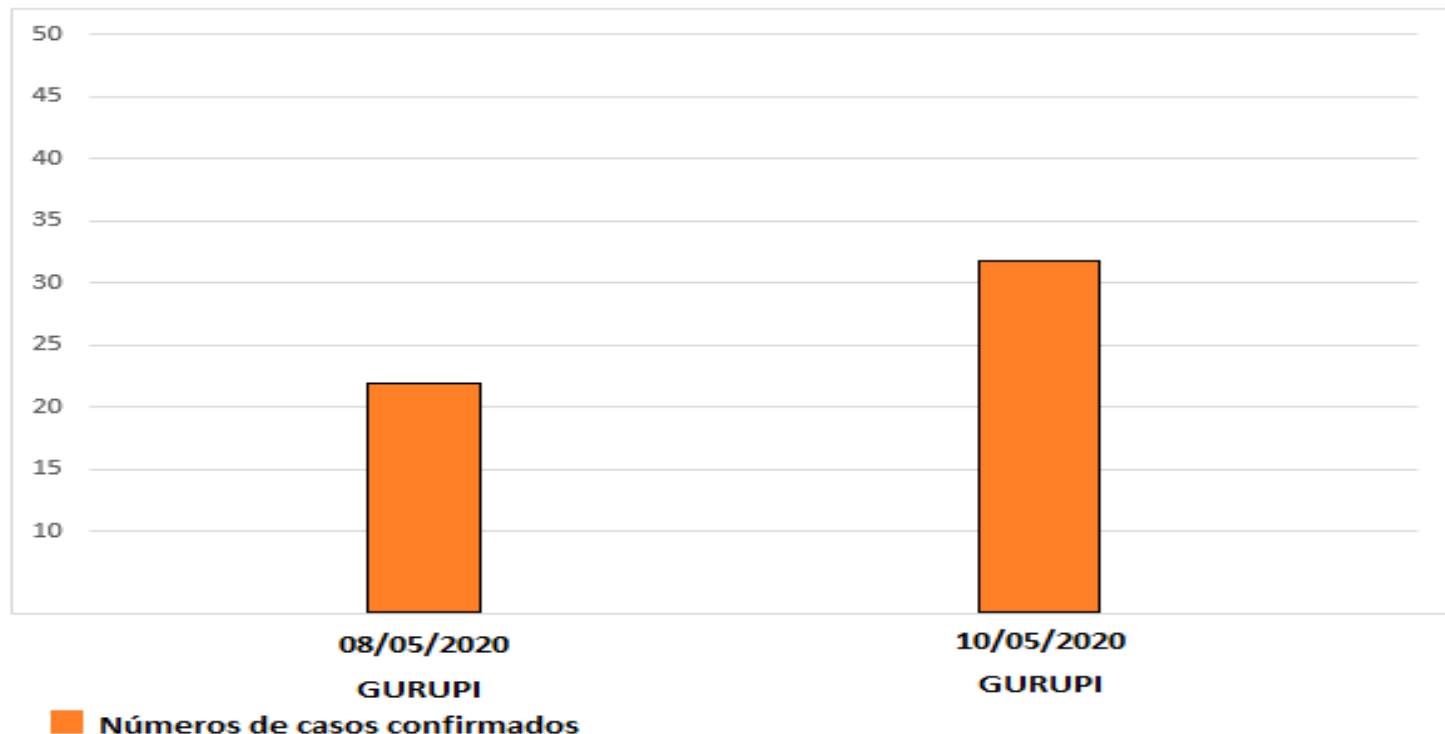

Gráfico 3: comparativo entre os dias 8 e 10 de maio da cidade de Gurupi- TO

\section{DISCUSSÁO}

O Estado do Tocantins até o dia 18 de março de 2020 não apresentava quaisquer casos confirmados de pessoas infectadas com o COVID-19, segundo consta no Boletim Oficial da Secretaria de Saúde do Estado do Tocantins, sendo que em tal data foi confirmado o primeiro caso na cidade de Palmas. ${ }^{17}$

A propagação do COVID-19 conforme observado nos diversos planos de contingenciamento, está claramente relacionada aos hábitos comuns das pessoas de terem contato umas com as outras, dado a própria característica do povo brasileiro de serem hospitaleiros, sendo que o combate da sua disseminação exige uma radical mudança nestes costumes, o que não se verificou até o momento, revelando ser esse um dos motivos do aumento do número de infectados após o primeiro caso reconhecido na cidade de Gurupi, que ocorreu no dia 08 de abril de $2020 .{ }^{14 .}$

É importante destacar que a data do conhecimento do primeiro caso na cidade de Gurupi pode não coincidir com a primeira pessoa contaminada, uma vez que a notificação de caso, somente ocorre após a confirmação de exames, que para ser diagnosticado necessita que o humano esteja com o vírus em seu organismo em prazo igual ou superior 
a 6 dias (período de incubação), bem como na dificuldade encontrada para a realização dos primeiros exames, seja pela falta de testes ou por falta de profissionais capacitados, logo tal situação pode ter refletido também no lapso entre o primeiro diagnostico no país e na cidade de Gurupi, que foi de mais de 40 dias. ${ }^{1}$

Diante do exposto, o que chama bastante atenção nessa pesquisa foi a rápida evolução em um prazo de 10 dias, aumentando em quase $550 \%$ o número de casos, que por sua vez demandam de uma infraestrutura de equipamentos de saúde e pode complicar ainda mais o combate a proliferação do vírus.

Cabe enfatizar ainda, que as possíveis causas do avanço podem se dar pelo fato de que algumas pessoas são assintomáticas e permanecem com a doença estável e controlada clinicamente, e por não exibirem os sintomas acabam não adotando as medidas de proteção e com isso proliferando o vírus.

Observou-se ainda, que o receio que as pessoas que apresentam os sintomas tem de informar ou buscar ajuda das autoridades sanitárias e de adotarem as medidas de isolamento social, meio este mais eficiente até o momento de conter a proliferação do vírus, ${ }^{14}$ tem de tal forma contribuído para a disseminação. ${ }^{19}$

Não descartando também que uma das hipóteses da rápida propagação do vírus se dá pelo fato da cidade de Gurupi estar localizada as margens de uma rodovia com intenso trafego, sendo que dentre esses, diversos profissionais caminhoneiros foram testados positivos para o COVID-19, e como a cidade por ter uma grande infra estrutura de posto de combustíveis em seu perímetro urbano e oferecer para os mesmos, condições ideais de pernoite, tornam-se assim locais de grande aglomeração, que somado ao fato dos profissionais transitarem por diversas unidades da federação em um curto período de tempo, são pessoas altamente expostas ao vírus, sendo tais locais propícios a proliferação do novo vírus, que combinado a circulação de pessoas da cidade pode ter refletido no aumento repentino de casos. ${ }^{14,15,16}$

Nessa situação os caminhoneiros passaram a ser foco de atenção, pois são profissionais que tem pouco ou nenhum acesso aos serviços de saúde, por viajarem continuamente por várias cidades e devido às longas jornadas de trabalho e aos muitos dias nas estradas ficando longe de suas cidades, podendo assim contribuir para a disseminação do vírus, além disso, comumente apresentam problemas de saúde, como: obesidade, hipertensão, alterações nos níveis de colesterol e ácido úrico, dores na 
coluna, diabetes, que para o MS são fatores de risco para agravos no quadro clínico e mortalidade no de contaminação por covid-19. ${ }^{15}$.

\section{CONSIDERAÇÓES FINAIS}

Até o dia 10 de maio de 2020 em Gurupi-TO, já havia sido registrado 32 casos confirmados do COVID-19, porém, segundo os estudos o número real de contaminados pode variar entre nove e quinze vezes mais que os casos notificados.

Diante do avanço exponencial do vírus na cidade, objeto desse estudo, tem sido necessária a adoção de estratégias e medidas de isolamento social, pois este é o meio comprovadamente mais adequado para a contenção da disseminação do vírus, combinado a isso deve ser aumentado a capacidade de leitos hospitalares exclusivo para tratamento de pessoas infectadas com o coronavíus, além de capacitação dos profissionais de saúde, bem como adotado uma testagem maior, a fim de identificar e isolar pessoas contaminadas para que não dissemine o vírus.

Logo a proteção da saúde pública deverá ser norteadora das decisões a serem tomadas pelos gestores, bem como as recomendações dos profissionais de saúde para que a população tenha uma vida fisicamente ativa deve ser encarada como uma importante abordagem para o combate ao COVID-19, e que essas decisões sejam fundamentais para que as evidências sejam disponíveis e comunicadas de forma transparente, promovendo a confiança da população.

Nesse contexto, é fundamental a atuação do Sistema Único de Saúde (SUS) e das demais áreas do sistema de proteção social de forma articulada, de modo a favorecerem a adesão das pessoas às informações, assim, é imperativo conhecer a população alvo e suas vulnerabilidades.

O estudo evidenciou ainda que o aumento de casos pode estar relacionado a localização da cidade as margem da BR 153 com alta aglomeração de caminhoneiros nos postos de combustíveis, elevando a exposição da cidade ao vírus e provocando sua disseminação, bem como pode ser também na ausência de medidas drásticas do poder público quanto ao isolamento social.

Outro fator que deve ser levado em consideração como uma das hipóteses é a ausência de simetria adotada entre as políticas do governo federal, estadual e municipal no combate da disseminação do vírus, uma vez que o governo federal adota um discurso 
mais liberativo quanto ao isolamento e o município não consegue controlar sua população através de medidas locais.

O presente artigo não apresenta um estudo conclusivo, uma vez que os dados e as informações públicas são insuficientes servindo o mesmo apenas para sugerir hipóteses das causas do drástico aumento ocorrido na cidade de Gurupi -TO, conforme sugeridas acima.

\section{REFERÉNCIAS}

1. Barreto Mauricio Lima, Barros Aluisio Jardim Dornellas de, Carvalho Marília Sá, Codeço Claudia Torres, Hallal Pedro Rodrigues Curi, Medronho Roberto de Andrade et al . O que é urgente e necessário para subsidiar as políticas de enfrentamento da pandemia de COVID-19 no Brasil?. Rev. bras. epidemiol. [Internet]. 2020 [cited 2020 May 03] ; 23: e200032. Available from: http://www.scielo.br/scielo.php?script=sci_arttext\&pid=S1415790X2020000100101\&lng=en. Epub Apr 22, 2020. [acessado em 02 de abril de 2020] http://dx.doi.org/10.1590/1980-549720200032.

2. Chate Rodrigo Caruso, Fonseca Eduardo Kaiser Ururahy Nunes, Passos Rodrigo Bastos Duarte, Teles Gustavo Borges da Silva, Shoji Hamilton, Szarf Gilberto. Presentation of pulmonary infection on CT in COVID-19: initial experience in Brazil. J. bras. pneumol. [Internet]. 2020 [cited 2020 May 07] ; 46( 2 ): e20200121. Available from:

http://www.scielo.br/scielo.php?script=sci_arttext\&pid=S1806$37132020000200300 \& \mathrm{Ing}=\mathrm{en}$. Epub Apr 09, 2020. [acessado em 02 de abril de 2020] http://dx.doi.org/10.36416/1806-3756/e20200121.

3. Croda JHR, Garcia LP. Resposta imediata da Vigilância em Saúde à epidemia da COVID-19. Epidemiol Serv Saúde [Internet]. 2020 [citado 2020 Mar 26];29(1):e2020002. [acessado em 03 de abril de 2020] https://doi.org/10.5123/s1679-49742020000100021

4. Ferreira Maycon Junior, Irigoyen Maria Cláudia, Consolim-Colombo Fernanda, Saraiva José Francisco Kerr, Angelis Kátia De. Vida Fisicamente Ativa como Medida de Enfrentamento ao COVID-19. Arq. Bras. Cardiol. [Internet]. [cited 2020 May 03]. Available from: http://www.scielo.br/scielo.php?script=sci_arttext\&pid=S0066782X2020005006201\&lng=en. In press 2020. Epub Apr 09, 2020. [acessado em 18 de abril de 2020] https://doi.org/10.36660/abc.20200235.

5. Fiho José Marçal Jackson, Assunção Ada Ávila, Algranti Eduardo, Garcia Eduardo Garcia, Saito Cézar Akiyoshi, Maeno Maria. A saúde do trabalhador e o enfrentamento da COVID-19. Rev. bras. saúde ocup. [Internet]. 2020 [cited 2020 May 03] ; 45: e14. Available from: http://www.scielo.br/scielo.php?script=sci_arttext\&pid=S030376572020000100100\&Ing=en. Epub Apr 17, 2020. [acessado em 18 de abril de 2020] https://doi.org/10.1590/2317-6369ed0000120.

6. Garcia Leila Posenato, Duarte Elisete. Intervenções não farmacológicas para o enfrentamento à epidemia da COVID-19 no Brasil. Epidemiol. Serv. Saúde [Internet]. 2020 [cited 2020 May 03] ; 29( 2 ): e2020222. Available from: http://www.scielo.br/scielo.php?script=sci_arttext\&pid=S2237- 
96222020000200100\&Ing=en. Epub Apr 09, 2020. [acessado em 20 de abril de 2020] https://doi.org/10.5123/s1679-49742020000200009.

7. Geovane Rossone Reis, Waldecy Rodrigues, Marcos Gontijo da Silva, Janne Marques Silveira, Marllos Peres de Melo, Érica Eugênio Lourenço Gontijo.Impact of Social Isolation on Public Health in Tocantins: a pathological, economic and social analysis of covid-19. Jornal Internacional Europeu de Ciência e Tecnologia. 2020 [acessado em 16 de abril de 2020].

8. Lima Claudio Márcio Amaral de Oliveira. Information about the new coronavirus disease (COVID-19). Radiol Bras [Internet]. 2020 Apr [cited 2020 May 03] ; 53( 2 ): V-VI. Available from: http://www.scielo.br/scielo.php?script=sci_arttext\&pid=S010039842020000200001\&Ing=en. Epub Apr 17, 2020. [acessado em 20 de abril de 2020] http://dx.doi.org/10.1590/0100-3984.2020.53.2e1.

9. Ministério da Saúde (BR). Portaria MS/GM n. 188, de 3 de fevereriro de 2020. Declara Emergência em Saúde Pública de importância Nacional (ESPIN) em decorrência da Infecção Humana pelo novo Coronavírus (2019-nCoV) [Internet]. Diário Oficial da União, Brasília (DF), 2020 fev 4 [citado 2020 mar 27]; Seção 1:1. [acessado em 20 de abril de 2020] http://www.in.gov.br/web/dou/-/ 241408388

10. Oliveira Wanderson Kleber de, Duarte Elisete, França Giovanny Vinícius Araújo de, Garcia Leila Posenato. Como o Brasil pode deter a COVID-19. Epidemiol. Serv. Saúde [Internet]. 2020 [cited 2020 May 03] ; 29( 2 ): e2020044. Available from: http://www.scielo.br/scielo.php?script=sci_arttext\&pid=S2237-

96222020000200200\&Ing=en. Epub Apr 27, 2020. [acessado em 26 de abril de 2020] http://dx.doi.org/10.5123/s1679-49742020000200023.

11.https://www.paho.org/bra/index.php?option=com_content\&view=article\&id=6101 :covid1 9\&ltemid=875 [acessado em 26 de abril de 2020].

12. https://saude.gov.br/component/tags/tag/oms.[acessado em 26 de abril de 2020]

13. Fatores associados ao comportamento da população durante $o$ isolamento social na pandemia de covid-19. Anselmo César Vasconcelos Bezerra, Carlos Eduardo Menezes da Silva, Fernando Ramalho Gameleira Soares, José Alexandre Menezes da Silva. Revista ciências e saúde coletiva [acessado em 10 de maio de 2020]. https://preprints.scielo.org/index.php/scielo/preprint/view/123/173

14. Sheila Araujo Teles, Marcos André de Matos, Karlla Antonieta Amorim Caetano, Ludmila Araujo Costa,Divânia Dias da Silva França, Grécia Carolina Pessoni, Sandra Maria Brunini, Regina Maria Bringel Martins. Comportamentos de risco para doenças sexualmente transmissíveis em caminhoneiros no Brasil. Rev Panam Salud, 2008 [acessado em 10 de maio de 2020] https://scielosp.org/article/rpsp/2008.v24n1/25-30/pt/

15. Sobrinho-Santos, Cleice Kelly, Silva, Adriana Vieira da, Malheiros, Antonio Francisco, Trindade, Reginaldo Almeida da, \& Pagan, Acacio Alexandre. (2015). Relatos de caminhoneiros sobre a prevenção do HIV e o material educacional impresso: reflexões 
para educação em saúde. Ciência \& Educação (Bauru), 21(4), 1011-1030.[acessado em 9 de maio 2020] https://doi.org/10.1590/1516-731320150040014

16. Penteado Regina Zanella, Gonçalves Claudia Giglio de Oliveira, Costa Daniele Damaris da, Marques Jair Mendes. Trabalho e saúde em motoristas de caminhão no interior de São Paulo. Saude soc. [Internet]. 2008 Dec [cited 2020 May 10] ; 17( 4 ): 35-45. Available from: http://www.scielo.br/scielo.php?script=sci_arttext\&pid=S0104$12902008000400005 \&$ Ing=en. [acessado em 8 de maio de 2020] https://doi.org/10.1590/S0104-12902008000400005.

17. https://g1 .globo.com/to/tocantins/noticia/2020/03/18/secretaria-confirma-primeiro-casode-coronavirus-no-tocantins.ghtml [acessado em 25 de abril de 2020].

18. https://cidades.ibge.gov.br/brasil/to/panorama.[acessado em 27 de abril de 2020].

19. Costa Fernandes Marcelo. Modelo de crença em saúde para determinantes de risco para contaminação por coronavíru. Revista de Saúde Pública. 2020 [acessado em 10 de maio de 2020]. http://www.rsp.fsp.usp.br/artigo/modelo-de-crenca-em-saude-paradeterminantes-de-risco-para-contaminacao-por-coronavirus/

20. http://www.gurupi.to.gov.br/?page=noticias\&id_not=4095 [acessado em 10 de maio de 2020]. 